\title{
A MEAN VALUE MODEL FOR ESTIMATION OF LAMINAR AND TURBULENT FLAME SPEED IN SPARK-IGNITION ENGINE
}

\author{
Ali Ghanaati ${ }^{1}$, Intan Z. Mat Darus ${ }^{1, *}$, Mohd Farid Muhamad Said ${ }^{2}$ and Amin \\ Mahmoudzadeh Andwari ${ }^{2}$ \\ ${ }^{1}$ Faculty of Mechanical Engineering, Universiti Teknologi Malaysia \\ 81310 Skudai, Johor, Malaysia \\ "Email: intan@fkm.utm.my \\ Phone: +6075557061; Fax: +6075566159 \\ ${ }^{2}$ Automotive Development Center (ADC), Universiti Teknologi Malaysia \\ 81310 Skudai, Johor, Malaysia
}

\begin{abstract}
Flame velocity is the main parameter for determination of combustion propagation in a spark-ignition engine. The first part of combustion that consists of flame initiation and flame kernel growth has laminar velocity. For a certain radius of kernel growth, transition to turbulent flame occurs; afterwards, the flame can be described as turbulent. This paper investigates the relationship between fuel properties and engine operation parameters, their influence on flame velocity and their ability to calculate the time delay from ignition to 50\% mass fraction burned (MFB) that is used for adjusting the spark advance. The GT-Power software is employed to simulate the combustion process of a spark-ignition (SI) engine. The flame speed mean value model is applied to determine the laminar flame speed under different amounts of unburned mixture, temperatures and pressures. The results show that mixture with less than the stoichiometric ratio has the greatest laminar flame speed. At higher temperature, the difference between poor and rich mixture is significant for laminar flame speed. On the other hand, the relationship between turbulence intensity and engine speed is almost linear. The cylinder pattern used to create turbulence during the intake and compression strokes defines the slope between the engine speed and turbulent flame speed. The mean value flame speed model was capable of determining the combustion phasing and predicting spark ignition in advance.
\end{abstract}

Keywords: Spark ignition engine; mean value model; laminar flame speed; turbulent flame speed; turbulence intensity; chamber geometry.

\section{INTRODUCTION}

The rate of flame travel in a spark-ignition engine cylinder is the main factor controlling the rate of pressure increase, and hence it has an important influence on engine performance [1]. The spark-ignition engine combustion rate is primarily dictated by the chamber geometry, the turbulent flame entrainment rate, and the laminar flame speed of mixture burn-up [2, 3]. The combustion flame propagation, distribution and disappearance can be simplified by a parametric model. Various flame structure models are applied in combustion calculations [4]. The mean flame front models are the ones that follow the simplest structure, where the turbulent flame is represented by its mean location. This approach works together with a flame geometry model in quasi- 
dimensional engine cycle simulations. The flame structure model accounts for the laminar flame speed, turbulent flame speed, and transition between these two. The flame speed model used in the flame structure model should provide values for those three quantities. The flame structure model may incorporate a model for the flame kernel initiation and development process [5-7]. The flame initiation and flame kernel growth during combustion are laminar. Transition to turbulent flame occurs until the flame has a radius of about $5 \mathrm{~mm}$; afterwards, the flame can be described as turbulent $[8,9]$. The flame structure model may apply different models for the laminar flame speed and turbulent flame speed, with the transition from laminar to turbulent being determined by a flame development angle [10, 11]. Otherwise, the flame structure model may incorporate a single model that calculates the flame speed at all stages, laminar, transition and turbulent [12]. Existing turbulent flame speed models are often a function of the laminar flame speed, the turbulence intensity and other scaling parameters. These models are generally the result of a correlation between experimental data and the scaling parameters. The scaling parameters are not always easily determined by ordinary instrumentation, and may be a limiting factor in the utilization of such models [13]. Combustion is initiated considering the product volume to be a very small percentage of the cylinder volume. The flame structure model previously assumed a laminar flame speed at the beginning of combustion, with an abrupt transition to turbulent flame at a specified flame development angle. Afterwards, combustion was assumed to be fully turbulent, where the turbulent flame speed was given by the laminar flame speed multiplied by a factor. The turbulent flame continued until the end of combustion $[14,15]$.

Laminar flame speed is a function of the mixture equivalence ratio, pressure, temperature, and residual gas fraction [16]. In-cylinder turbulence and flow patterns are influenced by the mean piston speed, intake parameters such as valve timing and port geometry, the length of the compression stroke during which there is turbulence decay, and combustion. The combustion chamber geometry and spark plug location affect the burn rate by altering the flame front area, determined by the interaction of the spherical flame front and combustion chamber walls. An accurate combustion model must therefore account for at least the effects of chamber geometry, laminar flame speed and in-cylinder turbulence [17, 18]. Nowadays, spark-ignition (SI) engines work with a variety of fuel types with different properties. On the other hand, engine operation requires a simple and accurate model to account for fuel variation. While the laminar and turbulent flame speed uses a complex formulation, a mean value model is proposed for turbulent flame speed. Gasoline was selected as the fuel and the simulation was run with engine operation boundaries such as intake pressure, intake temperature and stoichiometric mixture. Simulink MATLAB ${ }^{\circledR}$ was used for calculation of the flame speed parameters and GT-Power software was employed to apply the model to the combustion simulation $[19,20]$. A 1.6L 4-cylinder CAMPRO engine GT-Power model was used.

\section{METHODS AND MATERIALS}

\section{Formulation for Turbulent Flame Speed}

The turbulent flame speed model uses all the fundamentals related to spark-ignition engine combustion variables. The first assumption is that the flame structure model does not employ the flame development angle. The correlation between laminar and turbulent 
flame speed during a whole combustion event is described by Eq. (1). The model covers the combustion process from the initially laminar flame to the fully turbulent flame.

$$
\frac{S_{T}}{S_{L}}=1+\left(\frac{C R}{8}\right)^{a}\left(\frac{\rho_{u}}{\rho_{b}}\right)^{\phi_{1}}\left(\frac{p}{p_{i g}}\right)^{\phi_{2}}\left(0.5 \frac{\bar{S}_{P}}{S_{L}}\right)^{b}\left(1-\exp \left(-\frac{R_{f}}{c D}\right)\right)
$$

where $S_{T}$ is turbulent flame speed $(\mathrm{m} / \mathrm{s}), S_{L}$ is laminar flame speed and $(\mathrm{m} / \mathrm{s}), C R$ is compression ratio, $\rho_{u}$ and $\rho_{b}$ are density of the unburned and burned charge ahead of the flame, $p_{i g}$ and $p$ are cylinder pressure at the time of ignition and cylinder pressure (bar), $\bar{S}_{P}$ is mean piston speed $(\mathrm{m} / \mathrm{s}), R_{f}$ is flame radius $(\mathrm{m}), a, b$ and $c$ are constant coefficients, $D$ is cylinder bore (m) and $\phi_{1}$ and $\phi 2$ are fuel coefficients. By simplifying the engine running and cylinder geometrical parameters in Eq. (1) into $C$ as a coefficient, Eq. (2) is generated. The turbulence intensity of Eq. (2) has been defined as half of the mean piston speed in Eq. (1) [13].

$$
\frac{S_{T}}{S_{L}}=1+C\left(\frac{\rho_{\mathrm{u}}}{\rho_{b}}\right)^{\frac{1}{2}}\left(\frac{u^{\prime}}{S_{L}}\right)^{b}\left(1-\exp \left(-\frac{\mathrm{R}_{\mathrm{f}}}{r_{c}}\right)\right)
$$

The turbulence integral scale $r_{c}$ was assumed to correlate with the cylinder bore. The coefficients of Eq. (1) are set according to experiments. $\phi_{1}$ and $\phi_{2}$ are functions of the mixture equivalence ratio:

$$
\begin{aligned}
\phi_{1} & =d+e(\phi-1) \\
\phi_{2} & =f+g(\phi-1)
\end{aligned}
$$

The constant coefficients $d, e, f$ and $g$ are also adjusted by conducting the fuel experiments procedure.

\section{Laminar Flame Speed}

The laminar flame speed in Eq. (1) is calculated from the expression developed by [21]:

$$
S_{L}=S_{L, 0}\left(\frac{T_{u}}{T_{0}}\right)^{\alpha}\left(\frac{p}{p_{0}}\right)^{\beta}\left(1-2.06 F_{R}^{0.77}\right)
$$

where $T_{u}$ is unburned mixture temperature $(\mathrm{K}), T_{0}$ and $p_{0}$ are reference temperature (298 ${ }^{\circ} \mathrm{K}$ ) and pressure (1 atm), $S_{L, 0}$ is reference laminar speed, $\alpha$ and $\beta$ are temperature and pressure exponents for a given fuel. The last term in Eq. (5) is the correction to take into account the effects of the residual gas mass fraction. The values used for gasoline as the constant coefficients in Eqs. (1), (3) and (4) for the simulation were the following: $a=1.1, b=0.7, c=1.7, d=0.611, e=1.4, f=1.152$ and $g=-1.5$. These values were determined in such a way that the measured and calculated peak pressure coincide in value and take place at the same crank angle.

Eq. (6) is used for reference flame speed correction according to equivalence ratio variations [22]. 


$$
S_{L, 0}=B_{m}+B_{\phi}\left(\phi-\phi_{m}\right)^{2}
$$

where $B_{m}, B_{\phi}$ and $\phi_{m}$ are the fuel constants, $\phi$ and $\phi_{m}$ are the equivalence ratio and the equivalence ratio at which maximum flame speed occurs for the selected fuel [23].

\section{Turbulence Intensity Modeling}

The controls-oriented model is developed based upon the quasi-dimensional turbulent flame entrainment concept first introduced by [24] and refined by [25, 26] and finally propagated by [27]. The rate at which unburned mass is entrained by the flame front is described by Eq. (7). The flame is assumed to propagate through the unburned charge along Kolmogorov-scale vortices entraining turbulent eddies. The entrainment velocity is defined by the sum of a diffusive component, laminar flame speed, and a convective component, turbulence intensity. The flame front area is defined by the leading flame edge, not the total flame surface area enclosing the still unburned eddies. Of these parameters, the mass entrainment rate is most influenced by the turbulence intensity and flame front area [18]. Turbulence intensity is defined as the root-mean-squared velocity fluctuation within the cylinder [28], and is generally an order of magnitude larger than the laminar flame speed.

$$
\frac{d m_{e}}{d t}=\rho_{u} A_{f}\left(u^{\prime}+S_{L}\right)
$$

where $m_{e}=$ mass entrained by the flame, $\rho_{u}=$ density of the unburned charge ahead of the flame, $A_{f}=$ total flame front area, $u^{\prime}=$ turbulence intensity and $S_{L}=$ laminar flame speed.

After the turbulent flame entrainment, the mass burn-up rate can be described by Eq. (8). The burn-up rate is proportional to the total unburned mass entrained behind the flame front. Entrained turbulent eddies are then assumed to burn up at the laminar flame speed since the length scale is small. The eddy size is approximated as the Taylor micro-scale, which is the assumed length scale over which laminar diffusion occurs, justifying the use of the laminar flame speed in this case [25]. The Taylor micro-scale is calculated using Eq. (9). It is important to note that the Taylor micro-scale is a function of turbulence intensity.

$$
\frac{d m_{b}}{d t}=\frac{m_{e}-m_{b}}{\tau}
$$

where $m_{b}=$ total burned mass, $\tau=\lambda / S_{L}$, characteristic cell burn time and $\lambda=$ Taylor micro-scale of turbulence.

$$
\lambda / S_{L}=\left(\sqrt{\frac{15}{\xi}}\right)\left(\frac{u^{\prime} L}{v}\right)^{-\frac{1}{2}}
$$

where $\xi=1$ (assumption made by [25]), $L=$ integral length scale and $v=$ kinematic viscosity. 
Prior to ignition, the integral length scale is assumed equal to the instantaneous combustion chamber height [18]. After ignition, which is the period of interest here, unburned charge is compressed at such a rate that the rapid distortion theory (RDT) is assumed valid. The RDT is used when the timescale of the turbulence distortion rate is much shorter than the large eddy turnover or decay timescales [29]. The RDT assumes that angular momentum within the turbulent field is conserved, and that there is no interaction between turbulent eddies [30]. Rapid distortion theory defines the integral length scale during combustion by Eq. (10). The instantaneous chamber height at the time of the spark is calculated by dividing the cylinder volume by the bore area.

$$
L=L_{0}\left(\frac{\rho_{u 0}}{\rho_{u}}\right)^{\frac{1}{3}}
$$

where $L_{0}=$ chamber height at ignition, $\rho_{u 0}=$ unburned charge density at ignition, $\rho_{u}=$ unburned charge density during combustion.

The flame front area at each crank angle is interpreted from a geometrically calculated table. The flame-area table is generated using engine-specific combustion chamber geometry. Spherical coordinates, originating at the spark plug, are used to calculate a flame front area and burned gas volume for a range of radii at each crank angle. Additional information, such as flame/wall interaction areas with the piston, cylinder walls, and cylinder head, is also generated. The cylinder volume $V$ at any crank position $\theta$ is calculated by Eq. (11), where $s$ is the distance between the crank axis and the piston pin axis generated from Eq. (12).

$$
\begin{gathered}
V=V_{c}+\frac{B^{2}}{4}(l+a-s) \\
s=a \cos \theta+\left(l^{2}-a^{2} \sin ^{2} \theta\right)^{1 / 2}
\end{gathered}
$$

where $V_{c}$ is compression volume, $B$ is cylinder bore, $l$ is connecting road length, $a$ is crank radius [14]. Furthermore, the combustion chamber space simulated by using the engine cylinder head and piston drawing part are used for flame front area calculation.

The inverse-model is derived from the quasi-dimensional turbulent flame entrainment model introduced in the previous section. Eqs. (7) to (10) are solved for turbulence intensity using the following methodology. First, Eq. (8) is solved for the entrained mass (see Eq. (13)).

$$
m_{e}=m_{b}+\tau\left(\frac{d m_{b}}{d t}\right)
$$

The derivative of Eq. (13) is related to the rate of turbulent flame entrainment. The characteristic diffusive cell burn time, $\tau$, is assumed constant during differentiation to simplify calculations.

$$
\underbrace{\left(\frac{d \tau}{d t}\right)\left(\frac{d m_{b}}{d t}\right)}_{\text {Assume: }: d \tau / d t^{\prime}=0}+\tau\left(\frac{d^{2} m_{b}}{d t^{2}}\right)+\left(\frac{d m_{b}}{d t}\right)=\left(\frac{d m_{e}}{d t}\right)=\rho_{\text {unburned }} A_{\text {flame }}\left(u^{\prime}+S_{L}\right)
$$


To solve for Eq. (14), it is converted into a cubic polynomial (Eq. (15)). The cubic polynomial can be solved graphically or numerically. Only positive real roots of the polynomial are acceptable solutions for $u^{\prime}$. The mass-fraction burned curve from a single-zone heat release model is used as the input for the derivative of the massburning rate. The flame front area, laminar flame speed, and unburned gas density and temperature are also calculated at each crank angle.

$$
\begin{aligned}
u^{\prime 3}+2\left(S_{L}-\frac{1}{\rho A} \frac{d m_{b}}{d t}\right) u^{\prime 2}+\left(S_{L}^{2}+\frac{1}{(\rho A)^{2}}\left(\frac{d m_{b}}{d t}\right)^{2}+\frac{2 S_{L}}{\rho A} \frac{d m_{b}}{d t}\right) u^{\prime}= & \\
& \frac{15 L v}{\xi\left(\rho A S_{L}\right)^{2}}\left(\frac{d^{2} m_{b}}{d t^{2}}\right)^{2}
\end{aligned}
$$

Previous studies have demonstrated that the turbulence intensity scales linearly with the mean piston speed (MPS) [31]. The increase in turbulence intensity with engine speed occurs because the time duration of the intake stroke changes. For a given air and fuel mass, increasing engine speed will decrease the induction time and create high velocities at the intake valves. The slope of turbulence intensity with respect to mean piston speed varies with the engine design and operating condition. Typical slope values range from approximately 0.4 to 1.7 .

The base turbulence intensity level is determined from the mean piston speed and valve overlap using

$$
u^{\prime}=c_{1} V_{M P S}
$$

where $c_{1}=$ specific coefficient and $V_{M P S}=$ mean piston speed $(\mathrm{m} / \mathrm{s})$. The relationship between the RPM and MPS is

$$
V_{M P S}=\frac{2 n}{60} . l
$$

where $l$ is piston stroke and $n$ is engine speed (rpm). The standard fixed-cam engines generally have a period when both the intake and exhaust valves are open simultaneously, known as valve overlap. The valve overlap is designed into fixed-cam engines as a compromise that will allow function throughout the speed and load range of the engine. For this model, a $20^{\circ}$ overlap is assumed for calculation [2].

\section{RESULTS AND DISCUSSION}

The model was simulated using the Simulink MATLAB ${ }^{\circledR}$ and GT-Power softwares. Eqs. (5)-(6) are employed for laminar flame speed determination and Eqs. (15)-(17) are utilized for turbulent flame speed estimation. All the initial values assumed for gasoline and running parameters are chosen in the domain of the SI engine operating range. Table 1 shows the fuel properties and engine operating parameters during the simulation process. Figure 1 shows the variation of the laminar flame speed with equivalence ratio, temperature, and pressure. The phenomena of the laminar flame speed have an inverse behavior in lean and rich air-to-fuel conditions. Laminar flame speed variation at low temperature $\left(328^{\circ} \mathrm{K}\right)$ is negligible; however, by increasing the in-cylinder temperature, the laminar flame speed increases for poor mixtures and decreases in rich conditions. At higher temperatures, the difference between the poor and rich mixtures for laminar flame speed was significant. 
Table 1. Fuel properties and engine operation parameters.

\begin{tabular}{|c|c|c|c|}
\hline \multicolumn{2}{|l|}{ Fuel } & \multicolumn{2}{|c|}{ Engine } \\
\hline Property & Range & Parameter & Range \\
\hline$S_{L, 0}$ & $34-41 \mathrm{~cm} / \mathrm{s}$ & speed & $1000-6000 \mathrm{rpm}$ \\
\hline$\phi_{m}$ & 1.21 & intake temperature & $328-428^{\circ} \mathrm{K}$ \\
\hline$\alpha$ (temperature exponent) & $2.4-0.271 \phi^{3.51}$ & cylinder pressure & 4-10 bar \\
\hline$\beta$ (pressure exponent) & $-3.57+0.14 \phi^{2.77}$ & $\phi$ & $0.9-1.1$ \\
\hline$B_{m}$ & $35 \mathrm{~cm} / \mathrm{s}$ & valve overlap & $20^{\circ} \mathrm{CAD}$ \\
\hline$B_{\phi}$ & $-54.9 \mathrm{~cm} / \mathrm{s}$ & $\begin{array}{l}\text { intake valve } \\
\text { lifting }\end{array}$ & $0.15 \mathrm{~mm}$ \\
\hline
\end{tabular}

Figure 1(b) illustrates the relation between the laminar flame speed and the equivalence ratio at the time of ignition in a condition where the in-cylinder mixture temperature $\left(350{ }^{\circ} \mathrm{K}\right)$ and pressure $(1 \mathrm{bar})$ for gasoline (mean value model) and the experimental fuel are reported for a mixture of $80 \%$ iso-Octane plus $20 \%$ ethanol/ air [32]. Any increase in the cylinder pressure decreases the laminar flame speed. Different fuels have the same properties in very poor and very rich conditions, while the maximum laminar flame occurs around $\phi=1$.

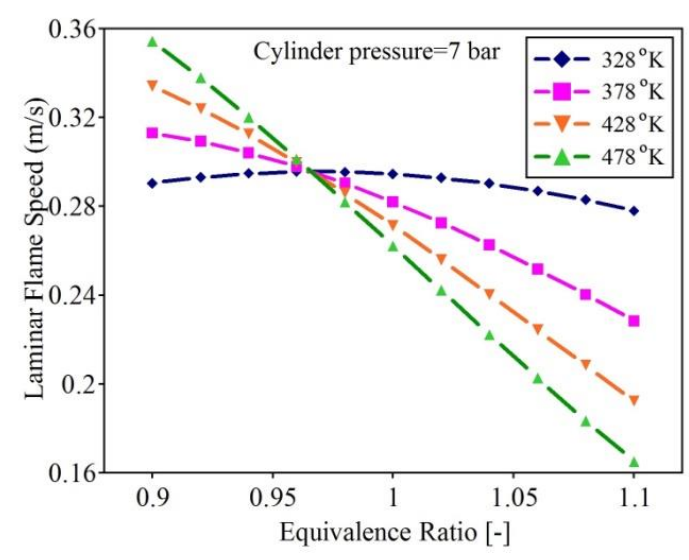

(a)

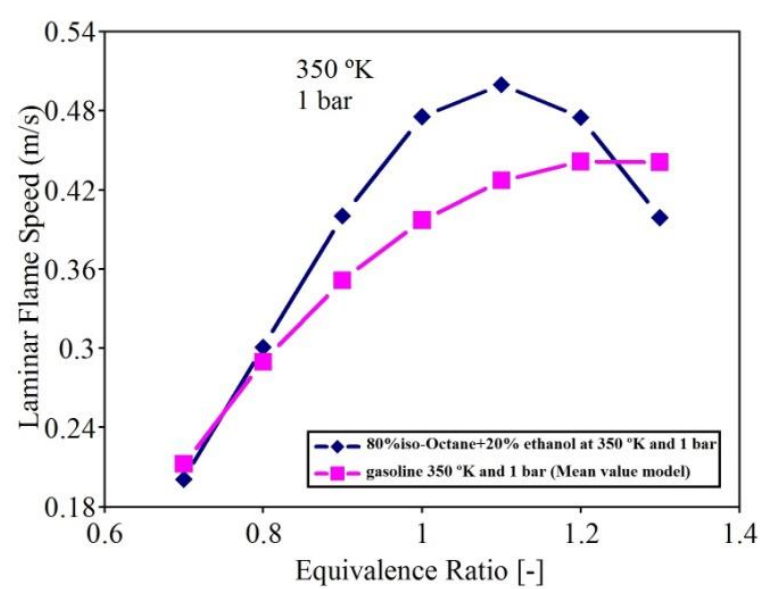

(b)

Figure 1. Laminar flame speed at different equivalence ratios with (a) cylinder temperatures; and (b) different fuels.

As a primary factor to determine the flame entrainment rate, turbulence intensity trends must be quantified throughout the engine operating range. A simple model for turbulence intensity prediction is also desirable for real-time spark timing prediction. Turbulence intensity predictions with respect to MPS follow a linear trend, as shown in Figure 2. The simulation was run at MBT timing, constant valve overlap, stoichiometric air-to-fuel ratio, and fixed engine load to isolate the influence of engine speed. The valve overlap has a direct influence on the slope between engine speed and turbulence intensity. As a result, each system that affects valve overlap - for instance, the variable 
valve timing (VVT) system - is required to take into account the valve overlap parameter.

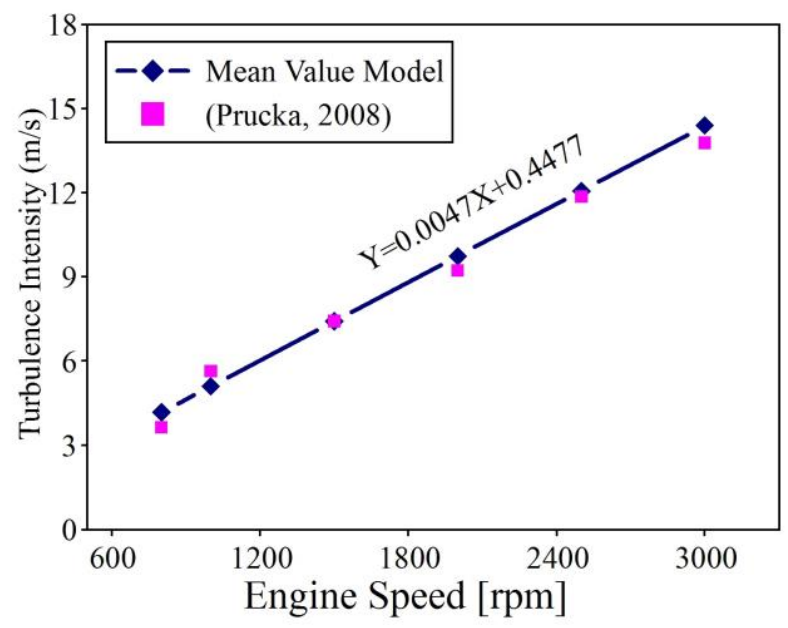

Figure 2. Relation between turbulence intensity and engine speed.

The location of $50 \%$ MFB was adjusted at $8^{\circ}$ aTDC for optimum combustion efficiency. The ignition timing was set to keep the combustion phasing at the desired value. Figure 3 shows the result of applying the mean value model to the engine combustion model, and the engine brake torque and brake power are also illustrated.

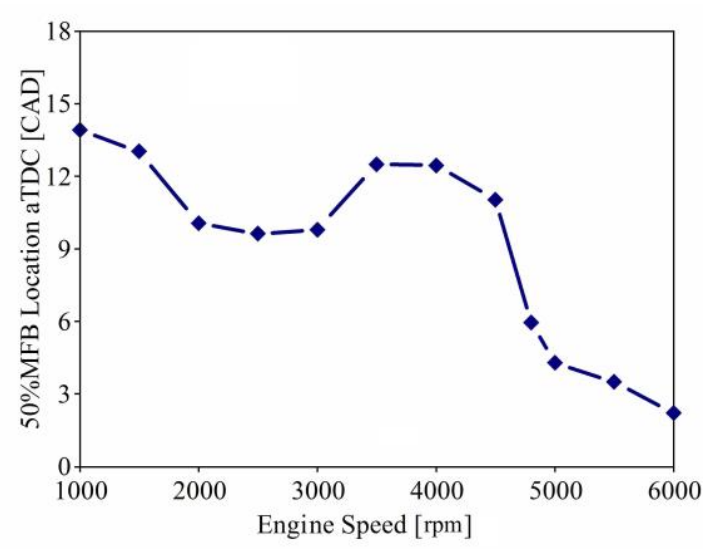

(a)

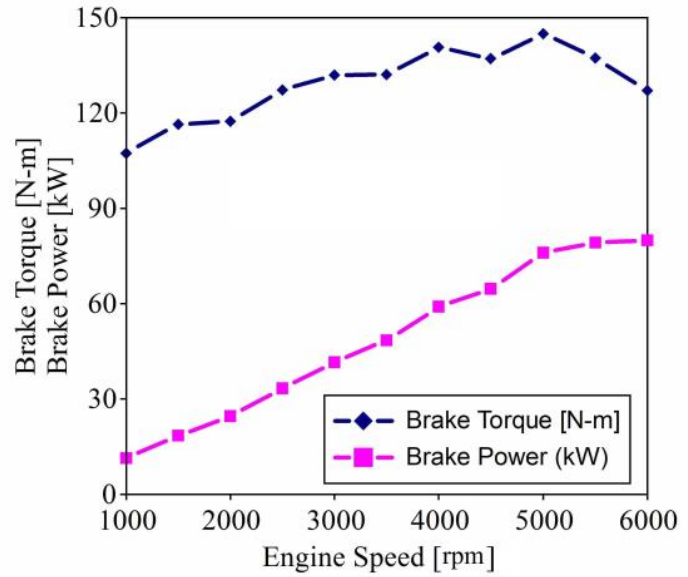

(b)

Figure 3. (a) The location of 50\% MFB; (b) engine brake torque and power.

\section{CONCLUSIONS}

The SI combustion investigation was performed to evaluate the laminar and turbulent burning speed of near-to-stoichiometry gasoline/air flames. These formulations are based on easily determined engine geometric and running parameters. The cylinder pattern to create turbulence during the intake and compression strokes defines the slope between the engine speed and turbulent flame speed. By substituting the complex turbulent formulation with a mean value model, the engine management system is able to control the engine online. 50\% MFB as the combustion phasing is accessible by utilizing this flame speed model. One goal of the mean value flame speed model is to 
develop techniques to predict the flame speed. Later, the flame velocity will be used to determine the combustion delay between the spark and 50\% MFB location. Therefore, the spark advance, as a most important control parameter that affects engine outputs such as torque, specific fuel consumption, and exhaust emissions, may be estimated.

\section{ACKNOWLEDGMENTS}

The authors would like to express their gratitude to Minister of Education Malaysia (MOE) and Universiti Teknologi Malaysia (UTM) for funding and providing facilities to conduct this research. This research is supported using FRGS Vote No. 4F395 and UTM Research University grant, Vote No. 05H71.

\section{REFERENCES}

[1] Jerzembeck S, Sharma A, Peters N. Laminar burning velocities of nitrogen diluted standard gasoline-air mixture. SAE Technical Paper No. 2008-01-1075; 2008.

[2] Prucka RG, Lee TK, Filipi Z, Assanis DN. Turbulence intensity calculation from cylinder pressure data in a high degree of freedom spark-ignition engine. SAE Technical Paper No. 2010-01-0175; 2010.

[3] Ghobadian B, Najafi G, Nayebi M. A semi-empirical model to predict diesel engine combustion parameters. Journal of Mechanical Engineering and Sciences. 2013;4:373-82.

[4] Verhelst S, Sheppard CGW. Multi-zone thermodynamic modelling of sparkignition engine combustion-an overview. Energy Conversion and Management. 2009;50:1326-35.

[5] Rahman MRA, Yokomori T, Ueda T. Model of flame dynamics of laminar premixed flame subject to the low frequency equivalence ratio oscillations. International Communications in Heat and Mass Transfer. 2015;61:8-15.

[6] Olesky LM, Martz JB, Lavoie GA, Vavra J, Assanis DN, Babajimopoulos A. The effects of spark timing, unburned gas temperature, and negative valve overlap on the rates of stoichiometric spark assisted compression ignition combustion. Applied Energy. 2013;105:407-17.

[7] Rostami S, Ghobadian B, Kiani Deh Kiani M. Effect of the injection timing on the performance of a diesel engine using diesel-biodiesel blends. International Journal of Automotive and Mechanical Engineering. 2014;10:1945-58.

[8] Bianco Y, Cheng WK, Heywood JB. The effects of initial flame kernel conditions on flame development in SI engine. SAE Technical Paper No 912402; 1991.

[9] Patil KR, Thipse SS. Characteristics of performance and emissions in a direct injection diesel fuelled with kerosene/diesel. International Journal of Automotive and Mechanical Engineering. 2014;10:2102-11.

[10] Sodré JR. Correlating turbulent flame speed to engine running parameters. SAE Technical Paper No. 973129; 1997.

[11] Hamada KI, Rahman MM. Experimental study performance emissions small four stroke SI engine modern motorcycle. International Journal of Automotive and Mechanical Engineering. 2014;10:1852-65.

[12] Herweg R, Maly RR. A fundamental model for flame kernel formation in SI engines. SAE Technical Paper No. 922243; 1992. 
[13] Sodré JR. A parametric model for spark ignition engine turbulent flame speed. SAE Technical Paper No. 982920; 1998.

[14] Heywood JB. Internal combustion engine fundamentals. New York: McGrawHill; 1988.

[15] Sai Yashwanth M, Venugopal T, Ramesh A. Experimental and simulation studies to determine the effective octane number in an engine fuelled with ethanol and gasoline. International Journal of Automotive and Mechanical Engineering. 2014;10:2057-69.

[16] Turns SR. An introduction to combustion : concepts and applications. 3rd ed. New York: McGraw-Hill; 2012.

[17] Poulos SG, Heywood JB. The effect of chamber geometry on spark-ignition engine combustion. SAE Technical Paper No. 830334; 1983.

[18] Filipi ZS, Assanis DN. The effect of the stroke-to-bore ratio on combustion, heat transfer and efficiency of a homogeneous charge spark ignition engine of given displacement. International Journal of Engine Research. 2000;1:191-208.

[19] Muhamad Said MF, Latiff ZA, Saat A, Said M, Abidin SFZ. Analysis of variable intake runner lengths and intake valve open timings on engine performances. Applied Mechanics and Materials. 2014;663:336-41.

[20] Muhamad Said MF, Abdul Aziz AB, Abdul Latiff Z, Mahmoudzadeh Andwari A, Mohamed Soid SN. Investigation of cylinder deactivation (CDA) strategies on part load conditions. SAE Technical Paper No. 2014-01-2549; 2014.

[21] Rhodes DB, Keck JC. Laminar burning speed measurements of Indolene-Airdiluent mixtures at high pressures and temperatures. SAE Technical Paper No. $850047 ; 1985$.

[22] Metghalchi M, Keck JC. Burning velocities of mixtures of air with methanol, isooctane, and indolene at high pressure and temperature. Combustion and Flame. 1982;48:191-210.

[23] Zhang P, Du Y, Wu S, Xu J, Li G, Xu P. Flame regime estimations of gasoline explosion in a tube. Journal of Loss Prevention in the Process Industries. 2015;33:304-10.

[24] Blizard NC, Keck JC. Experimental and theoretical investigation of turbulent burning model for internal combustion engines. SAE Technical Paper No. $740191 ; 1974$.

[25] Tabaczynski RJ, Ferguson CR, Radhakrishnan K. A turbulent entrainment model for spark-ignition engine combustion. SAE Technical Paper No. 770647; 1977.

[26] Tabaczynski RJ, Trinker FH, Shannon BAS. Further refinement and validation of a turbulent flame propagation model for spark-ignition engines. Combustion and Flame. 1980;39:111-21.

[27] Kaprielian L, Demoulin M, Cinnella P, Daru V. Multi-zone quasi-dimensional combustion models for spark-ignition engines. SAE Technical Paper No. 201324-0025; 2013.

[28] Tennekes H, Lumley JL. A first course in turbulence. Cambridge, Massachusetts: MIT Press; 1972.

[29] Durbin PA, Zeman O. Rapid distortion theory for homogeneous compressed turbulence with application to modelling. Journal of Fluid Mechanics. 1992;242:349-70.

[30] Wong VW, Hoult DP. Rapid distortion theory applied to turbulent combustion. SAE Technical Paper No. 790357; 1979. 
[31] Abraham J, Williams FA, Bracco FV. A discussion of turbulent flame structure in premixed charges. SAE Technical Paper No. 850345; 1985.

[32] Syed IZ, Yeliana Y, Mukherjee A, Naber J, Michalek D. Numerical investigation of laminar flame speed of gasoline-ethanol/air mixtures with varying pressure, temperature and dilution. SAE International No. 2010-010620. 2010;3:517-28. 